\title{
CLINIC AND THERAPEUTIC ASPECTS IN DUCTUS-DEPENDENT CONGENITAL HEART DEFECTS - PART I
}

\author{
Alina-Costina Luca ${ }^{1}$, Andreea-Simona Holoc, Mirabela Subotnicu, \\ Constantin Iordache \\ ${ }^{1} 1^{\text {st }}$ Clinic of Pediatrics, , Sf. Maria“ Children's Hospital, \\ „, Gr. T. Popa “ University of Medicine and Pharmacy, Iaşi
}

\begin{abstract}
Congenital heart defects with ductus-dependent circulation have a complex cardiovascular physiology. After birth, the condition of these children is critical, they are asymptomatic and their pulmonary vascular resistance decreases leading to progressive hemodynamic deterioration. Early identification of these defects and the start of appropriate therapy allow to maintain the cardiovascular balance.

Keywords: congenital heart defect, ductus-dependent systemic circulation, persistence of
\end{abstract} ductus arteriosus, E1 prostaglandin

Congenital heart defects with ductus-dependent circulation are defined as abnormalities, in which the permeability of the ductus arteriosus is mandatory in order to maintain systemic perfusion. Ductus arteriosus permeability is given by the presence of an abnormal communication between the proximal descending aorta and the vicinity of left branch of the pulmonary artery (1).

In the womb, gas exchanges and metabolic reactions occur in placenta, shortcutting the lungs. First breath makes them fill with air and leads to increased pulmonary flow and later cutting the umbilical cord leading to increased systemic vascular resistance and lowering the pulmonary one resulting in the closure of the three shunts. If these events do not occur, the fetal circulation will continue after birth (15-17).

Transition circulation and fetal shunts closure occur as in healthy new-borns even if the new-born has a ductus-dependent heart defect, initially it is asymptomatic (5).
Later, through progressive narrowing of the ductus arteriosus appear the signs reflecting the systemic hypoperfusion $(5,7)$ :

- pallor;

- coldness;

- weak felt pulse;

- tachycardia;

- tachypnea;

- hypotension;

- anuria;

- progressive acidosis;

- cardiovascular Collapse.

Ductus-dependent congenital heart defects are divided into ductus-dependent systemic and pulmonary.

Ductus-dependent systemic circulation diseases are:

- critical aortic valve stenosis in the neonate;

- hypoplastic left heart syndrome;

- aortic coarctation;

- interrupted aortic arch. 


\section{CRITICAL AORTIC STENOSIS}

When the aortic orifice surface is reduced to less than a quarter of the normal value, overcoming the obstacle and provision of ventricular ejection is achieved by increasing highest systolic pressure in left ventricle to overcome the pressure in the aorta.

Pressure overload causes hypertrophy of left ventricle and gradually left heart failure installs which in time becomes global (8). Hypertrophied left ventricle becomes noncompliant and the diastolic pressure grows causing pulmonary edema.

In critical aortic stenosis, the left ventricle is unable to provide adequate antegrade cardiac output, systemic circulation being ensured by the right ventricle through ductus arteriosus directly into the aorta.

The aortic arch, cerebral and coronary circulation are infused backwards with blood with relatively low oxygen saturation.

As the ductus arteriosus closes, systemic perfusion is compromised realizing a low cardiac output.

In this moment, clinical signs of systemic hypoperfusion appear, namely, pallor, tachypnea, tachycardia and hypotension (8.9).

\section{HYPOPLASTIC LEFT HEART SYNDROME}

It is a set of heart abnormalities that cause the obstruction of the outflow tract of the left ventricular outflow tract. These abnormalities include: stenosis/atresia or aortic valve orifice, ascending aorta/aortic arch hypoplasia, hypoplasia or mitral valve stenosis, hypoplasia of left ventricle (2).

Adequate systemic perfusion is ensured by the permeable ductus arteriosus. The flow of blood ejected from the right ventricle gets into the pulmonary arteries through the ductus arteriosus into the aorta. From the aorta blood advances backwards through the descending aorta into the lower half of the body and with a relatively low blood oxygen saturation and in the upper half of the body also through the descending aorta to the coronary arteries.

Progressive narrowing of the channel lowers blood pressure, multiorgan hypoperfusion, including acute coronary myocardial hypoperfusion and acidosis, and if ductus arteriosus closes, the prognosis is unfavorable, and the baby dies (5).

After birth, functional signs are minor. With the narrowing of the ductus arteriosus during their first weeks of life, the child's condition worsens, with the emergence of cyanosis, tachypnea, tachycardia, hypotension, weakly perceptible peripheral pulse or absent, rapidly developing pulmonary edema
(3.6). Metabolic acidosis and hypoglycemia appear, indicating systemic hypoperfusion.

\section{CRITICAL AORTIC COARCTATION}

Heart congenital defects characterized by narrowing and obstruction of the aorta in the descending part and often in the isthmus.

Aorta obstruction has the following consequences:

- In proximal areas of the obstacle, the hemodynamics is accompanied by increased pressure in the arteriolar bed of the cephalic end, upper limbs and pulmonary bed with left ventricle overload $(5,10)$.

- In post-ductal regions (the arteries supplying the lower limbs and abdominal organs) occurs vascular hypotension, vascularization being ensured by a network of collaterals between subclavian arteries and mammary arteries $(5,10)$.

In ductus arteriosus closure, the entire cardiac output must pass through the bottleneck to the descending aorta. When the coarctation is severe (critical), the left ventricle cannot provide adequate antegrade flow into the descending aorta, therefore, the systemic flow to the lower end of the body is ductus-dependent. $(11,12)$

In severe forms of the disease, signs of life appear in 7-10 days, through signs of congestive heart failure brutally installed and clinically presented through: tachypnea, cyanosis (especially in the legs), cold lower extremities weakly perceptible pulse or absent in femoral and Pedi arteries, acute renal failure (oliguria, anuria), shock, oxygen saturation difference between the upper and lower limbs $(5,11)$. Also, there is a difference of more than 10-15 mmHg in blood pressure between upper and lower limbs. Presence of pulmonary rales stasis and hepatomegaly appear.

\section{INTERRUPTED AORTIC ARCH}

Congenital heart defect is the discontinuity between the ascending and the descending aortas and a critical obstruction in the systemic circulation.

The flow in the descending aorta depends on the presence of permeable ductus arteriosus. With the decrease of the resistance in the pulmonary vascular bed (after the first week of life), increases the pulmonary flow with the occurrence of heart failure. When the ductus arteriosus has a tendency to closure, appear tissue hypoxia, metabolic acidosis and prerenal failure $(5,12)$. 
As through ductus arteriosus, the lower half of the body receives blood, here cyanosis often occurs. If it is associated with large DSV, it will improve pulmonary blood oxygen saturation.

\section{PHARMACOLOGICAL TREATMENT OF CONGENITAL HEART DEFECTS WITH DUCTUS-DEPENDENT SYSTEMIC CIRCULATION}

Recommendations:

- Oxygenation improvement with caution to avoid closure of the ductus arteriosus, opting to maintain oxygen saturation of $75-85 \%$ (5).

- Maintaining the permeability of ductus arteriosus by administering a dose of prostaglandin E1 0.05-0.1 mcg/kg/min (4).

- Patients diagnosed late will require high doses of prostaglandin E1 (0.15-0.20 mcg/ $/ \mathbf{k g} /$ min) with careful monitoring of adverse effects: respiratory depression and even apnea, hypocalcemia, hypoglycemia, hypotension, bradycardia or tachycardia, convulsions $(4,13)$.

- After ductus arteriosus permeability, overloading the pulmonary circulation using inhibitors of angiotensin converting enzyme (Captopril $1 \mathrm{mg} / \mathbf{k g}$ ) shall be avoided when blood pressure is normal or high, or phosphodiesterase inhibitors - Sildenafil 0.5-1 mg/ $\mathbf{k g} /$ dose shall be used when the blood pressure is low $(13,14)$.

- Diuretics are used, the preparation of choice Spironolactone $1 \mathrm{mg} / \mathrm{kg}$ in 1 to 3 doses may increase the retention of salt at $1-2 \mathrm{mg} / \mathrm{kg} /$ day in 1-3 divided doses.

- In severe forms of congestive heart failure, Furosemide $1 \mathrm{mg} / \mathrm{kg} / \mathrm{dose}$ is associated until diuresis of more than $3 \mathrm{ml} / \mathrm{kg} /$ hour is achieved, the dose can be repeated over 6-12 hrs; in the absence of the effect, the dose can be repeated after 2 hours.

- The increase circulation to normal volume using the volume-expander $(0.9 \%$ saline or
Ringer Lactate) in the amount of $10 \mathrm{ml} / \mathrm{kg}$ administered intravenously.

- Severe metabolic acidosis must be treated with $4.2 \%$ sodium bicarbonate (in an amount $2 \mathbf{~ m E q} / \mathbf{k g c} / \mathbf{d o s e}$ ) administered intravenously very slow, the equivalent of $\mathbf{2 - 4} \mathbf{~ m l} / \mathbf{k g c} /$ dose with adequate ventilation.

- Correction of rhythm disorders

- To maintain heart compliance, shall be administered $(13,14)$ :

- Inotropic - Dopamine, in case of reduced cardiac contractility; administered $5-20 ~ \mathbf{~ c g} / \mathbf{k g} / \mathbf{m i n}$ intravenously with infusion on the pump.

- Digoxin 0.04 mgkge saturation dose every 8 hours in the first day, followed by a maintenance dose, the $1 / 4$ dose of the saturation dose in two divided doses.

The child will be monitored, the saturation dose being achieved through intravenous administration and the maintenance dose may be administered orally.

If clinical signs appear, such as food refusal, vomiting, impaired general condition, or electrocardiographic signs (PQ prolongation, underleveled ST, ventricular arrhythmia), it is considered that there was an overdose or poisoning with Digoxin, and the following measures shall be taken:

- Digoxic administration termination;

- Oxygen therapy;

- Correction of electrolyte disturbances;

- Vigorous anti-arrhythmic treatment in bradyarrhythmias - Atropine 0.02-0.03 mg/kg and in tachyarrhythmias - Lidocaine in bolus of $0.5-1 \mathrm{mg} / \mathrm{kg}$ the initial dose, the subsequent doses 0.02-.0.3 mg/kgc/min.

\section{CONCLUSIONS}

In the neonatal period, multiple congenital heart defects may be overlooked due to patient's ductus arteriosus contributing to maintenance of a poor clinical picture but with extremely severe evolution at the closure of ductus arteriosus.

\section{REFERENCES}

1. Douglas J. Schneider, John W. Moore Patent Ductus Arteriosus. Circulation 2006; 114:1873-1882;

2. Knowles R., Griebsch I., Dezateux C., Brown J. Newborn screening for congenital heart defects: a systematic review and costeffectiveness analysis. Health Technol Assess 2005; 9(44):1-152

3. Nadas A.S., Fyler D.C. Hypoxemia. In: Keane JF, Lock JE, Fyler DC, editors. Nada's pediatric cardiology. 2nd edition. Philadelphia: Saunders Elsevier; 2006:97-101

4. Tálosi G., Katona M., Rácz K., Kertész E., Onozó B., Túri S. Prostaglandin E1 treatment in patent ductus arteriosus dependent congenital heart defects. J Perinat Med. 2004; 32(4):368-74.

5. Sin Weon Yun. Congenital heart disease in the newborn requiring early intervention. Korean J Pediatr 2011; 54(5): 183-191.

6. Barron D.J., Kilby M.D., Davies B., Wright J.G., Jones T.J., Brawn W.J. Hypoplastic left heart syndrome. Lancet. 2009; 374(9689):551-64 
7. Yee L. Cardiac emergencies in the first year of life. Emerg Med Clin North Am 2007; 25:981-1008

8. Mitchell B.j., Brown S.C. Management of severe aortic valve stenosis in the neonate: neonatal aortic valve stenosis. SA Heart. 2014; 11:4-11

9. Jessica H. Mouledoux, William F. Walsh. Evaluating the Diagnostic Gap: Statewide Incidence of Undiagnosed Critical Congenital Heart Disease Before Newborn Screening With Pulse Oximetry. Pediatric Cardiology 2013; 34:1680-1686

10. David J. Driscoll, Robert E. Shaddy, Timothy F. Feltes Moss \& Adams. Heart Disease in Infants, Children, and Adolescents: Including the Fetus and Young Adult. 8th Edition, Lippincott Williams \& Wilkins 2012

11. Damien Kenny, Ziyad M. Hijazi Coarctation of the aorta:From fetal life to adulthood. Cardiology Journal 2011; 18(5): 487-495

12. Julien I.E. Hoffman, James H. Moller. Pediatric Cardiovascular Medicine. John Wiley \& Sons, 2012
13. I.B. Vijayalakshmi, P. Syamasundar Rao, Reema Chugh. A Comprehensive Approach to Congenital Heart Diseases. JP Medical Ltd 2013, 5:89-93

14. Helmut Baumgartner, Philipp Bonhoeffer, Natasja M.S. De Groot, Fokko de Haan, John Erik Deanfield et al. ESC Guidelines for the management of grown-up congenital heart disease (new version 2010) The Task Force on the Management of Grown-up Congenital Heart Disease of the European Society of Cardiology (ESC). European Heart Journal, 2010

15. Toganel R. Cardiopatiile congenitale critice, in: Deleanu D., Progrese in cardiologie 2010", Editura T3 info, 2010:129-138.

16. Balas Broka R. Persistenta circulatiei fetale, in: Deac R., Toganel R. Ghid de diagnostic si tratament in bolile congenitale cardiovasculare la nou-nascut", Editura University Press, 2004: 21-33.

17. Steclari T., Rudi M. etc. Malformatii congenitale cardiace - Volumul I, Editura Tipografia Centrala, 2008: 71-79. 